\title{
Saponins from Tribulus Terrestris Linn Plant: Potentials and Challenges for Prevention of Solar Ultraviolet Radiation-Induced Damages and Malignant Transformation
}

\author{
Margherita Sisto* and Sabrina Lisi \\ Department of Basic Medical Sciences, Italy \\ *Corresponding author: Margherita Sisto, Department of Basic Medical Sciences, Italy
}

\begin{tabular}{|c|c|}
\hline ARTICLE INFO & ABSTRACT \\
\hline Received: 㓞 March 25, 2019 & \multirow{3}{*}{$\begin{array}{l}\text { There is a growing scientific interest in herbal medicine, and the promising results } \\
\text { obtained in herbal anti-inflammatory and anti-cancer therapy have progressively stim- } \\
\text { ulated research into the medicinal use of plants. One of the goals of anti-inflammatory } \\
\text { and anti-tumor therapy is the discovery of plant extracts that are relatively selective to } \\
\text { cancer and inflammatory cells. Tribulus terrestris L. (TT) is one such saponin-containing } \\
\text { herb used from antiquity to energize and improve sexual function in men, but new evi- } \\
\text { dence has shown that saponins also have a cytostatic activity against cancer cells and an } \\
\text { anti-inflammatory effect in several organs. This paper intends to review the most recent } \\
\text { reports on the properties of TT and investigate on the role of TT-derived saponins on the } \\
\text { modulation of apoptosis in normal human keratinocytes and in human squamous cell } \\
\text { carcinoma exposed to physiological doses of UVB, their possible anti-tumoral capacity, } \\
\text { and the molecular mechanisms underlying these properties. }\end{array}$} \\
\hline Published: April 08, 2019 & \\
\hline $\begin{array}{l}\text { Citation: Margherita Sisto, Sabrina } \\
\text { Lisi. Saponins from Tribulus Terrestris } \\
\text { Linn Plant: Potentials and Challenges } \\
\text { for Prevention of Solar Ultraviolet Radi- } \\
\text { ation-Induced Damages and Malignant } \\
\text { Transformation. Biomed J Sci \& Tech } \\
\text { Res 16(5)-2019. BJSTR. MS.ID.002911. }\end{array}$ & \\
\hline
\end{tabular}

Keywords: Tribulus terrestris L; Saponins; Squamous Cell Carcinoma; UVB; NER Genes

\section{Introduction}

One of the goals of anticancer therapy and prevention is the discovery of bioactive compounds that are relatively selective to tumor cells and therefore have reduced effects on normal cell growth. In addition, herbal therapy was used for thousands of years for the care of the inflammatory processes. The plants that contain saponins possess a broad range of bioactivities and were been commonly used in folk medicine for their health-promoting properties [1-4]. The genus Tribulus, belonging to family Zygophyllaceae, comprises about 20 species in the world [5] and among them, Tribulus terrestris Linn (TT) is a best-known officinalis herb by alternative medicine [6]. The TT is a perennial creeping plant which grows in subtropical areas and it is also distributed along a wide geographic perimeter that includes China, Japan, Korea, the western part of Asia, the southern part of Europe and Africa. The plant is used both as an individual therapeutic agent or in combination to other formulations of many compounds and food supplements [7]. The fruits of TT were used in traditional oriental medicine for the treat ment of the eye inflammation, skin irritation, abdominal pain, hypertension, cardiovascular disease and to improve sexual function and physical performance in men [8-12].

It is also a very potent diuretic and tonic drug $[13,14]$. Many active compounds from TT extract have been identified [15-17]. A literature survey showed that TT contains steroidal saponins, natural glycosides, which possess a wide range of pharmacological properties including a strong antioxidant effect, cytotoxic activity, and anti-inflammatory and anticarcinogenic capacities [18,19]. Therefore, the TT saponins have shown a potential photoprotective effect when the human skin cells were exposed UVB irradiation [20]. The numerous biological activities associated with saponins have led to great interest in their characterization and in the investigation of their pharmacological and biological properties. Information on the biological capacities of saponins from variety of sources provided important guidelines for the development and design of new drugs. The focus of this review is to provide an updated overview 
of various aspects of the biological properties of the saponins extracts of the TT plant, to highlight a photoprotective effect against UVB-induced skin carcinogenesis, and to demonstrate the molecular mechanisms through which TT saponins regulate cell death.

\section{Bioactive Compounds of Tribulus Terrestris}

A wide range of compounds have been extracted from TT such as saponins, flavonoids, glycosides, alkaloids and tannins [17,21-31]. Among these compounds, a number of phytochemical studies have demonstrated that saponins are responsible for the biological activities of TT extracts [32-34] and a wide range of pharmacological applications. Structurally, saponins are composed of a lipid-soluble aglycone that consists of a steroidal or triterpenoid skeleton and a water-soluble moiety, composed of sugar residues. The amphiphilic or surfactant properties of saponins derive from hydrophilic properties of the sugar part and lipophilic properties of the aglycone part; this, in turn, determines the ability of saponins to compose the stable aqueous foams and form complexes with membrane steroids and lipid compounds (Figure 1) [35]. Focusing on the phytochemical characteristics of the whole plant extract led to the identification of eleven new furostanol saponins, one new spirostanol saponin, and seven known steroidal saponins $[13,21,36]$.

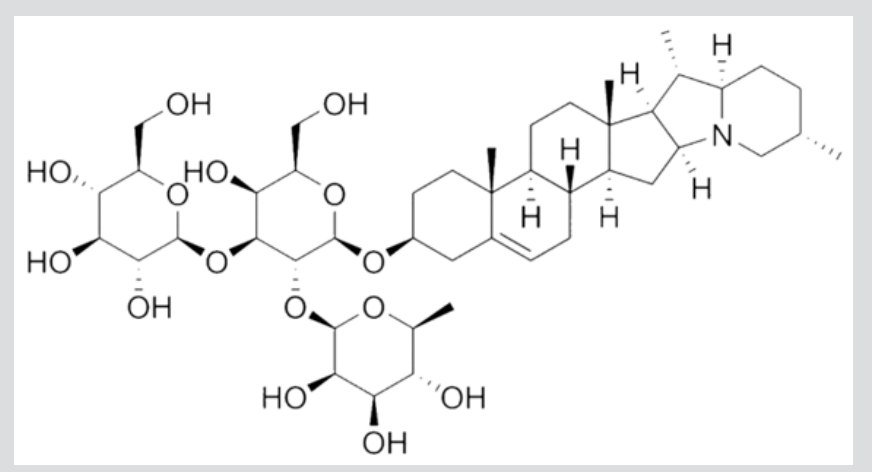

Figure 1: Chemical structure of saponin.

\section{TT Saponins Properties in Cancer Prevention and Treat- ment of Inflammatory Conditions}

Inflammatory diseases are a major cause of morbidity worldwide and non-steroidal anti-inflammatory drugs and steroids are the most common widespread drugs used for the treatment of acute or chronic inflammatory conditions. These drugs possess different side effects such as a gastrointestinal injury that is one of the most common side effect associated with the currently use of the nonsteroidal anti-inflammatory drugs which limit their application. This may be contributing to the current move by wide part of world population towards the officinalis herbs for the treatment of inflammation that characterizes numerous diseases. Actually, herbal medicine is still widely used by about $75-80 \%$ of the whole population for primary healthcare because of their efficacy, safety and very little side effects. However, the last few years have seen a major increase in their use in the developed world [37]. A number of medicinal plants were used in developing countries for the management of a number of disease conditions including cancer and inflammatory conditions.

The validation of the traditional assertions of these medicinal herbs will provide scientific basis for the conservation of oriental and tropical medicinal resources, the deployment of the beneficial ones as phytomedicine in the primary health care and the development of potential bioactive constituents as novel key compounds or precursors in drug design. At the class of phytoconstituents belong saponins that are heterogeneous group of naturally occurring surface active glycosides common in a large number of plants [38-39]. Growing evidence for natural products linked with their physicochemical features and numerous biological activities has led to the emergence of saponins as commercially significant compounds with expanding applications in the field of nutrition, cosmetics and pharmaceutical industries [40]. Steroidal saponins are important bioactive compounds for the production of steroidal hormones and drugs [41]. Saponins are used as immunological adjuvants in the formulation of vaccines due to their immune enhancing properties [39].

Later studies have allowed identifying saponins as inductors of cell death by means of several molecular mechanisms. The steroidal saponin constituents obtained from TT are well known to exhibit antimicrobial and cytotoxic effects [19,32,42,43], to induce apoptosis in liver cancer cells [44], as well as having antihyperlipidemic properties $[45,46]$ and improving reproductive function, libido and ovulation [17,47]. Saponin extracts from TT show strong antioxidant effects and some also show the biochemical effects in human cells, such as enzyme inhibition, antiinflammatory and anticarcinogenic capacities [47]. Recently, it was demonstrated the anti-inflammatory effect of saponins from extracts of TT on the pathological process of atherosclerosis. In this study, one of the more significant results was that TT suppressed proliferation of the Vascular Smooth Muscle Cells (VSMCs) induced by angiotensin II [48]. The VSMCs proliferation induced by various growth factors contributes to a variety of pathological processes including atherosclerosis [49]. The VSMC contribute to vessel wall inflammation and to the formation of the fibrous cap providing stability to the plaque [49].

Angiotensin II is the active protein of the renin-angiotensin system and it is involved as a potent growth factor for VSMCs, and it has been reported to be implicated in the VSMCs proliferation and promotes the generation of ROS [50]. TT acts as a potent antioxidant inhibiting the increase of the intracellular ROS and subsequently suppressing the VSMCs proliferation. These findings provide a new insight into the anti-atherosclerotic and antiinflammatory properties of the TT yielding a pharmacological basis for the clinical application in the atherosclerotic process. Tribulusin, gross saponins derived from TT was demonstrated to have a 
significant protective role against ischemia/reperfusion injury documented in rat hearts and brains in vitro and in vivo [51-54]. Anti-inflammatory effects have been investigated in vitro also with the aqueous extract of TT. In fact, TT extract blocks proliferation and triggers apoptosis in human liver cancer cells through the $\mathrm{NF}-\kappa \mathrm{B}$ signalling inhibition [55]. A recent study examined the effects of TT extracts demonstrating a strong inhibition of COX-2 and iNOS activity in cultured mouse macrophage cells stimulated with lipopolysaccharide [56]. Some evidence indicates that TT consumption may be useful in lowering serum cholesterol levels and the cardiovascular damage associated with hypercholesterolemia. A recent study examined the effects of TT extracts on the lipid profile and vascular endothelium of the abdominal aorta in New Zealand rabbits fed a cholesterol-rich diet [57]. The serum lipid profiles of animals treated with TT were significantly lower than those fed a high cholesterol diet without TT treatment. In the TTtreated rabbits, TT seems to protect from endothelial damage, indicating that dietary intake of TT can significantly modify serum lipid profiles, decrease endothelial modifications and rupture and may partially repair the endothelial dysfunction resulting from hyperlipidemia [57]. Furthermore, the anti-inflammatory activity of TT has been studied in the arthritic rats revealing a marked decrease of the acute inflammatory response [58], and, in the last years, recent studies demonstrated that the saponins have a conspicuous role in cancer prevention because of their antioxidant, anti-inflammatory, and growth-inhibitory effects [39,59] and are considered of the potent candidates for photoprotective applications [18]. The bioactive characteristics of TT saponins are summarized in Figure 2.

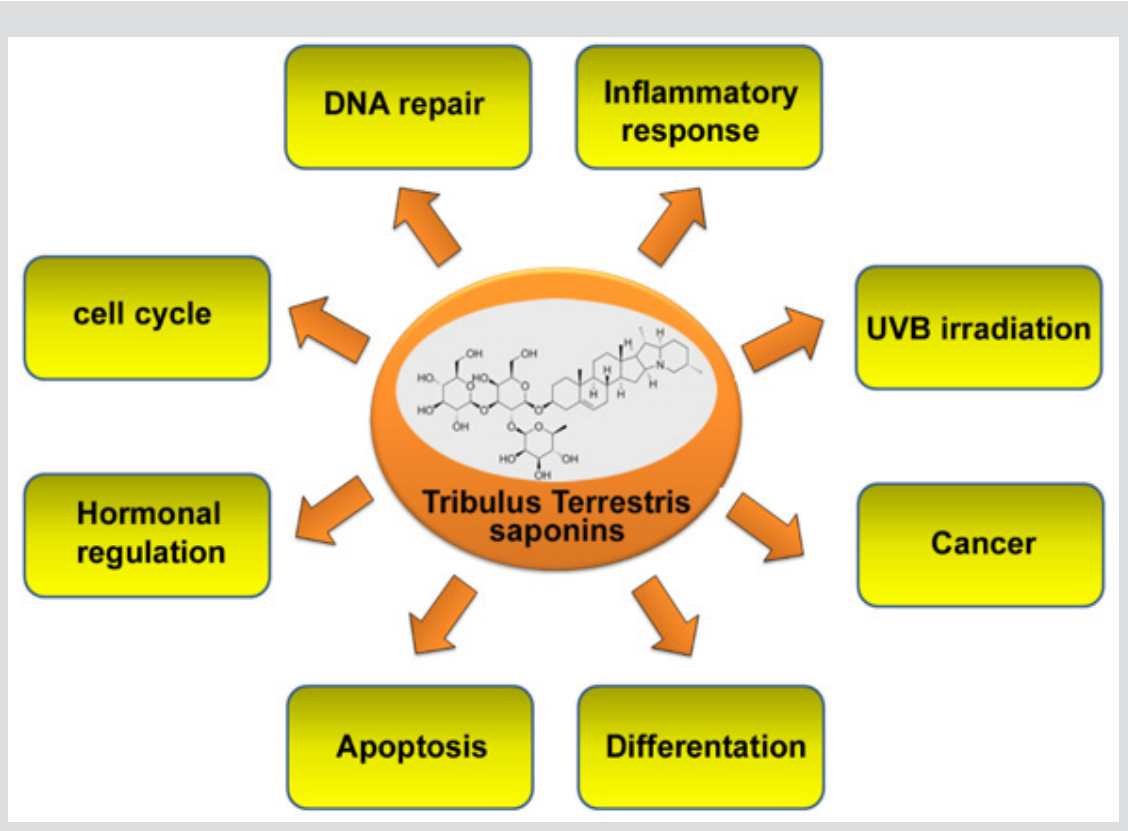

Figure 2: Multiple properties of saponins derived from Tribulus terrestris Linn.

\section{UVB-Dependent DNA Lesions}

The production of Reactive Oxygen Species (ROS) that derives from UV skin exposure can cause oxidative damage reacting with DNA and other cellular components proteins, resulting in the alteration of cell metabolism, morphology, differentiation, proliferation and apoptosis of skin cells [60]. These processes can lead to photoaging and skin cancer development. The photoprotective effect of antioxidant is now generally accepted and recently naturally occurring herbal compounds have received notable interesting contributing to the beneficial health effects [61]. UV radiation, in particular the middle wavelength (UVB, range 290$320 \mathrm{~nm}$ ), can be harmful to human health because it induces cancer, premature skin aging, immunosuppression, and cell death [62-64]. UV-induced DNA damage is the crucial molecular trigger for many UV-induced effects, such as apoptosis, immunosuppression, and carcinogenesis [65-67]. Although UVB radiation has less than $1 \%$ of total solar energy, the major types of DNA damage in the skin are provoked by UVB [68]. To exert its biological effects, UVB must be first absorbed by cellular chromophore, which transforms the energy into a biochemical signal. Subsequent photobiochemical reactions provoke changes in cell and tissue biology resulting in increased photoaging and skin cancer occurrence.

The bases of nucleic acids (DNA and RNA) and proteins are good cellular chromophores [69]. The major classes of UVBinduced DNA lesions are represented by cyclobutane-pyrimidine dimers and pyrimidine-pyrimidone photoproducts. Under normal conditions these photolesions are removed by the Nucleotide Excision Repair (NER) [70]. Xeroderma pigmentosum is a disease which reflects genetic defects in different components of the NER complex. Consequently, patients suffering from this disease are 
hypersensitive to the induction of genomic mutations by UV and show a dramatically increased incidence of skin cancer [71]. To limit the survival in the presence of irreparable DNA damage, cells die by apoptosis [72]. To induce programmed cell death, UVB uses a variety of cellular signalling pathways. In this case the induction of nuclear DNA damage appears to be the main pathway, since experimental suppression of DNA damage was linked to a strong reduction of apoptosis [72]. UVB was found to directly activate cell surface death receptors, thus inducing the apoptotic pathway. UVB induces the formation of the ROS associated to the mitochondrial damage and furthermore, cytochrome c release was demonstrated to be additionally involved in the apoptotic machinery.

The possibility to add exogenous DNA repair enzymes into the cell contributed highly to the elucidation of the critical role of UVBinduced DNA altered in mediating the various biological effects of UVB, including apoptosis. Following irradiation of cells with UVB, the tumor suppressor gene p53 was found to be upregulated proportionally to the amount of cyclobutane pyrimidine dimers inserted into genomic DNA [73]. p53 appears to be critically involved in the formation of apoptotic keratinocytes [74]. In this context the mitochondrial apoptotic pathway and the regulatory bcl-2 protein family appear to play an important role. The balance of proapoptotic and antiapoptotic members of the bcl-2 protein family addresses whether apoptosis is promoted or prevented [75]. In this scenario, antiapoptotic proteins avoid mitochondrial permeability transition and subsequent release of cytochrome $\mathrm{c}$ as well as of ROS into the cytoplasm [76-78]. In addition, UVB is known to be a potent inducer of ROS within the cell. These products have shown themselves to initiate cellular damage and apoptosis [79]. Therefore, ROS have been implicated in cutaneous aging as well as in the pathogenesis of inflammatory skin diseases and of skin cancer [80]. The cytotoxic potential of ROS involves lipid peroxidation leading to an alteration in the structure of cytoplasmic membranes [81] and impairment of the inner mitochondrial membrane resulting in dysfunction of the membrane potential and consequently in cytochrome c release into the cytoplasm [82].

TT Saponins in the Prevention of UVB-Induced Skin Damage: Effect on Apoptotic Pathways

UVB-induced DNA damage is a crucial molecular trigger for sunburn cell formation and skin cancer. The exposure of the skin to solar UVB on earth has both short-term and long-term deleterious wavelength-dependent effects on skin. Short term effects after sun exposure cause tanning and sunburn while, in contrast, long-term exposure to UVB provokes photoaging and photocarcinogenesis. UV radiation is the major etiologic factor in skin cancer because of its potent ability to induce DNA lesions. If the latter are not removed, they can cause mutations and subsequently skin cancer. There have been considerable efforts to search for naturally occurring substances that intervene in photodamage and photoaging. Interestingly, some of these anticancer drugs are developed from natural sources such as plants. Recently, it was found that ginsenoside Rb1, pharmacologically active components of ginseng, a steroidal saponins, inhibits cell apoptosis induced by UVB. This inhibition of ginsenoside Rb1 appears to be caused by a marked reduction in UVB-induced DNA damage, protecting cells through the induction of DNA repair, most likely NER system [83]. Likewise, latterly, it was demonstrated that glycyrrhizic acid, a triterpenoid saponin glycoside, to protect against UVB-mediated photodamage by inhibiting the signalling cascades triggered by oxidative stress, including NF- $\mathrm{BB}$ activation, as well as apoptosis in human keratinocyte cell line [84].

The TT saponins may have an important role in cancer prevention because of their antioxidant, anti-inflammatory, and growth-inhibitory properties [13]. Recently, Sisto et al. [20], investigated TT saponins effects on some parameters such as apoptotic pathway in Normal Human Keratinocytes (NHKs) as well as in malignant keratinocytes after exposure to physiological doses of UVB [20]. It has been amply demonstrated that human keratinocytes undergo programmed cell death following UVB exposure. The induction of apoptosis is considered to be a protective function against skin cancer, and the intrinsic apoptotic mechanism has been shown to be critical in this protective mechanism, ensuring the removal of UVB-damaged human keratinocytes and potentially transformed cells [85]. The authors, to demonstrated the protective effect of TT saponins, investigated cell survival of human epithelial keratinocytes derived from normal skin tissue (NHEK) after UVB irradiation demonstrating that TT saponins significantly increased their resistance to UVB and seem to help NHEK to preserve the typical epithelial morphology. Since a controlled apoptotic response is vital for skin cells, as it prevents the replication of cells containing damaged DNA, TT saponins determine cellular survival by inhibiting apoptosis.

Infact, TT saponins decreased the levels of caspases involved in the intrinsic apoptotic pathway induced by UVB irradiation and prevented both the leakage of cytochrome $c$ from mitochondria and UVB-induced DNA fragmentation [20]. To investigate the diverse effect of TT saponins treatment in normal keratinocytes and malignant cells after UVB irradiation, Sisto et al. [20], tested the effects of TT saponins on the apoptotic pathway in human Squamous Cell Carcinoma (SCC), demonstrating that TT saponins treatment reduced viability of the SCC cell and increased the DNA ladder formation following UVB exposure. These data suggest that saponins exert a wide range of differential activities in normal versus malignant cells determining the inhibition of the tumor growth of cancerous cells and triggering a selective apoptotic process [20]. This mechanism was reported in Figure 3.

\section{Efficacy of TT Saponins DNA Damage Repairing Mecha- nism in UVB-Exposed NHEK}

UVB exposure cause, as major event, the trigger of apoptotic pathway of keratinocytes and this results into epidermis sunburn 
cells induction [73]; The formation of sunburn cells in UV-exposed skin indicates the severity of DNA damage and this underlines the importance of DNA repair mechanisms in UVB-exposed skin cells. If cells are not repaired, they may continue to replicate and may lead to cutaneous malignancies. This means that DNA repair process is a protective mechanism [86]. The NER system is one of the major mechanism of DNA repair in mammalian cells [87]. NER is an excision mechanism that removes DNA damage induced by Ultraviolet Light (UV) characterized by the generation of thymine dimers and 6,4-photoproducts. Recognition of the damage leads to removal of a short single-stranded DNA segment that contains the lesion. The undamaged single-stranded DNA remains and DNA polymerase uses it as a template to synthesize a short complementary sequence. DNA ligase realized the final ligation to complete NER and form a double stranded DNA [87]. There is a list of major proteins involved in NER in mammalian cells, and, between these, Xeroderma pigmentosum, complementation group $\mathrm{C}$, also known as XPC and Xeroderma pigmentosum, complementation group A, also known as XPA, are two proteins which deficiencies are linked to alterations in the NER system $[87,88]$.

Importantly, TT saponins were demonstrated to have the capacity to repair DNA damage in UVB-exposed cells in the early phase of exposition. When NHEK were exposed to UVB and treated or not with TT saponins, the levels of XPA and XPC NER genes expression increased significantly as compared to non-UVB-exposed control NHEK and the protective effect of TT saponins against UVB irradiation resulted in a selective DNA damage response [20]. On the contrary, in already transformed malignant SCC, the levels of the XPA and XPC genes expression resulted not significantly altered following UVB irradiation, thus demonstrating that TT saponins increase the abundance of NER transcripts in UVB-irradiated healthy keratinocytes, but not in malignant transformed cells [20]. Therefore, TT saponins, acting on the NER system as molecular target, may have a preventive action on the risk of developing UVB-induced skin cancer, allowing the cells more able to repair the photodimers through nucleotide excision repair system (Figure 3).

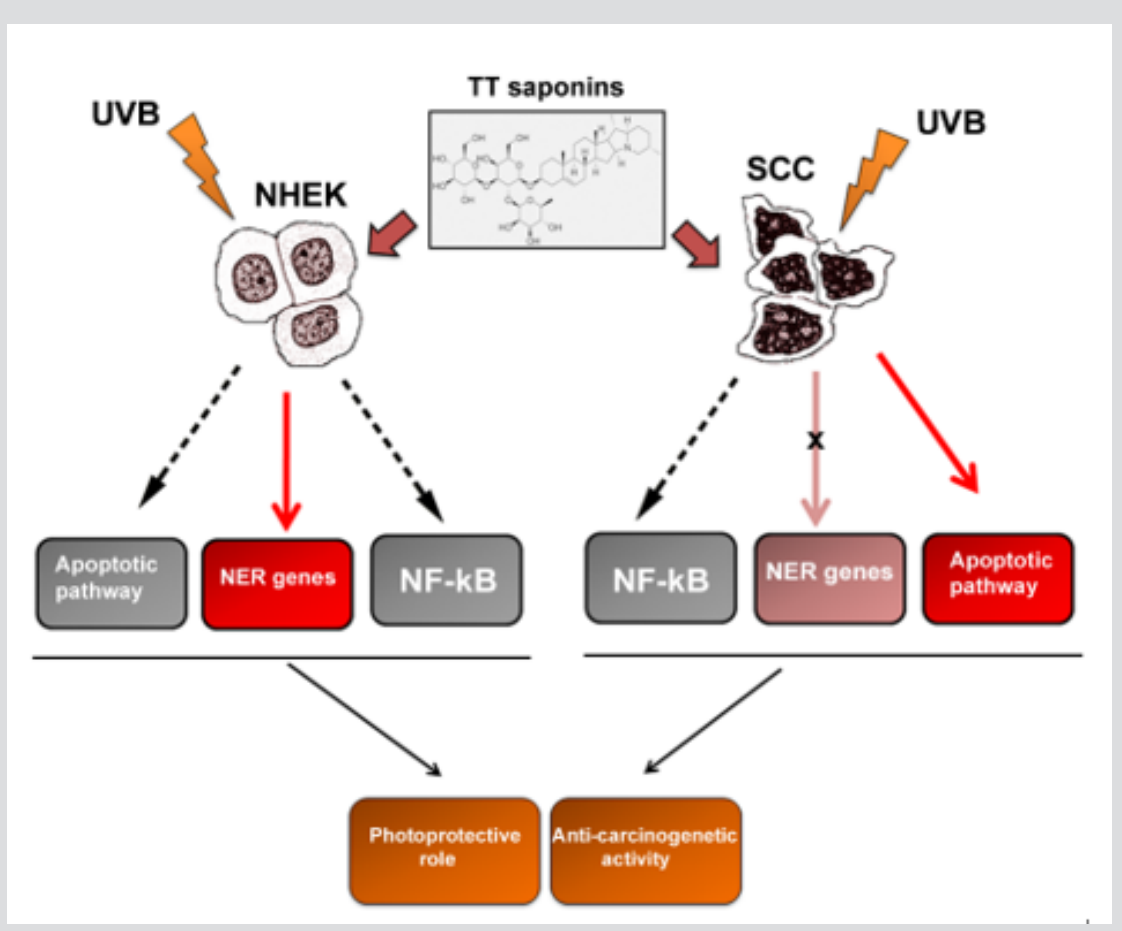

Figure 3: Schematic representation of the hypothetical mechanisms adopted from TT saponins to prevent UVB radiationinduced DNA damages, apoptosis and malignant transformation. The scheme shows that, in Normal Human Epithelial Keratinocytes (NHEK) exposed to physiological doses of UVB, TT saponins inhibit the activation of the intrinsic apoptotic pathway, determine an enhancement of NER genes expression to repair DNA damages, and block UVB-mediated NF$\mathrm{KB}$ activation. In already transformed Squamous Cell Carcinomas (SCC), TT saponins provoke an enhanced apoptosis in response to UVB irradiation, a block of the proliferation of human cancer cells through inhibiting NF-kB signalling, although an unchanged expression of the NER genes was revealed.

\section{NF-кB as Molecular Target of TT Saponins}

In many cell types, the activation of the NF- $\kappa \mathrm{B}$ signalling cascade serves to protect cells from a variety of cellular stresses that could lead to malignant transformation $[89,90]$. In most tumors, there is higher NF- $\kappa \mathrm{B}$ expression and activity when compared to the adjacent normal tissues, but such expression strongly depends on the tumor cell types and stage of development [91]. Many evidence support the fact that alteration of the NF- $\kappa$ B signalling pathway lead to changes in keratinocytes cell growth and epidermal thickness, causing a homeostatic breakdown, resulting in a loss of function [92]. Furthermore, a variety of agents which determine tumori- 
genesis (such as UVB radiation, phorbol esters and TNF-alpha), are noted to modulate NF- $\kappa B$ signalling, suggesting that NF- $\kappa$ B plays a role in suppressing carcinogenesis [93-95]. In this contest, TT saponins, through inhibiting NF- $\kappa B$ signalling, have been shown to block the proliferation of human cancer cells [55]. Recently, Sisto et al. [20] demonstrated that the inhibition of the NF- $\kappa B$ pathway could be responsible for the chemopreventive properties of TT saponins against UVB-mediated skin carcinogenesis [20]. Exposure to UVB irradiation provokes an activation of NF- $\mathrm{\kappa B}$, both in normal and malignant cells, as measured by an increase in specific DNA binding and, like in normal cells, also in malignant cells, an inhibition of NF$\kappa \mathrm{B}$ activation occurs following TT saponins treatment that demonstrate an anti-tumorigenic activity of T. Terrestris L. (Figure 3) [20].

\section{Conclusion}

Tribulus terrestris $L$. is a well-known plant used in indigenous medicine especially in urogenital system, nervous, cardiovascular, and musculo-skeletal system disorders. Modern literature recognizes multiple beneficial properties to TT biologically active phytoconstituent and saponins, in particular, have antitumor effect on many cancer cells; actually, there are significant scientific reports and data available regards the photoprotective efficacy of these TT constituents and recent research demonstrated that TT saponins resulted to have a dual-efficacy to prevent malignant transformation of epithelial cells caused by UVB exposure. In fact, TT saponins, on one hand, protect healthy keratinocytes by UVB irradiation-dependent damage and, on the other, enhance UVBcaused apoptosis in squamous cell carcinoma, thus suggesting that TT saponins possibly work as UVB-damage sensors to exert their biological action. Together, these findings encourage further mechanistic and in vivo studies for developing TT saponins as a promising chemopreventive and/or chemotherapeutic agent against UVB-caused skin alteration and tumors in humans.

\section{Acknowledgment}

We are grateful to M.V.C. Pragnell, B.A., for critical reading of the manuscript. This study was supported by Grant (No: 20216000056) from the Italian Ministry for Universities and Research.

\section{References}

1. Hu K, Yao X (2002) Protodioscin: Its spectrum of cytotoxicity against sixty human cancer cell lines in an anticancer drug screen panel. Planta Medica 68: 297-301.

2. Hu K, Yao X (2003) The cytotoxicity of methyl protodioscin against human cancer cell lines in vitro. Cancer Invest 21: 389-393.

3. Jiang Y, Wang N, Yao X, Susumu K (1998) Structural elucidation of the anticoagulation and anticancer constituents from Allium chinense. Yao Xue Xue Bao 33: 355-361.

4. Wang SL, Cai B, Cui CB, Liu HW, Wu CF, et al. (2004) Diosgenin-3-O-alphaL-rhamnopyranosyl-(1 --> 4)-beta-D-glucopyranoside obtained as a new anticancer agent from Dioscorea futschauensis induces apoptosis on human colon carcinoma HCT-15 cells via mitochsondria-controlled apoptotic pathway. J Asian Nat Prod Res 6: 115-125.

5. Trease GE, Evans WC (2002) A taxonomic approach to the study of medicinal plants and animal derived drugs. Trease and Evans
Pharmacognosy. (15 th $e d n$.). Singapore: Harcourt Brace and Company Asia Pvt. Ltd, p. 27.

6. Duke J, Duke PK, Cellier JL, Mary Jo BG (2002) Duke Handbook of medicinal herbs. ( $2^{\text {nd }}$ edn.). United States: CRC Press, pp. 595-597.

7. Nadkarni KM (1927) Indian Materia Medica. Mumbai: Popular Prakashan, pp. 1230-1241.

8. Sharifi AM, Darabi R, Akbarloo N (2003) Study of antihypertensive mechanism of Tribulus terrestris in $2 \mathrm{~K} 1 \mathrm{C}$ hypertensive rats: role of tissue ACE activity. Life Sci 73: 2963-2971.

9. Adimoelja A (2000) Phytochemicals and the breakthrough of traditional herbs in the management of sexual dysfunctions. Int J Androl 23: 82-84.

10. Santos CA, Reis LO, Destro-Saade R, Luiza-Reis A, Fregonesi A (2014) Tribulus terrestris versus placebo in the treatment of erectile dysfunction: A prospective, randomized, double blind study. Actas Urol Esp 38: 244-248.

11. Wang SS, Ji YS, Li H, Yang SJ (2009) Mechanisms of gross saponins of Tribulus terrestris via activating PKC epsilon against myocardial apoptosis induced by oxidative stress. Yao Xue Xue Bao 44: 134-139.

12. Sancar A, Lindsey-Boltz LA, Unsal-Kaçmaz K, Linn S (2004) Molecular mechanisms of mammalian DNA repair and the DNA damage checkpoints. Annu Rev Biochem 73: 39-85.

13. Chhatre S, Nesari T, Somani G, Kanchan D, Sathaye S (2014) Phytopharmacological overview of Tribulus terrestris. PharmacognRev 8: 45-51.

14. Al-Ali M, Wahbi S, Twaij H, Al-Badr A (2003) Tribulus terrestris: Preliminary study of its diuretic and contractile effects and comparison with Zea mays. J Ethnopharmacol 85: 257-260.

15. Cai L, Wu Y, Zhang J, Pei F, Xu Y, et al. (2001) Steroidal saponins from Tribulus terrestris. Planta Medica 67: 196-198.

16. De Combarieu E, Fuzzati N, Lovati M, Mercalli E (2003) Furostanol saponins from Tribulus terrestris. Fitoterapia 74: 583-591.

17. Huang JW, Tan CH, Jiang SH, Zhu DY (2003) Terrestrinins A and B, two new steroid saponins from Tribulus terrestris. J Asian Nat Prod Res 5: 285-290.

18. Lacaille-Dubois MA, Wagner $H$ (1996) A review of the biological and pharmacological activities of saponins. Phytomedicine 2: 363-386.

19. Podolak I, Galanty A, Sobolewska D (2010) Saponins as cytotoxic agents: A review. Phytochem Rev 9: 425-474.

20. Sisto M, Lisi S, D Amore M, De Lucro R, Carati D, et al. (2012) Saponins from Tribulus terrestris $L$. protect human keratinocytes from UVBinduced damage. J Photochem Photobiol B 117: 193-201.

21. Kang LP, Wu KL, Yu HS, Pang X, Liu J, et al. (2014) Steroidal saponins from Tribulus terrestris. Phytochemistry 107: 182-189.

22. Tomowa MP, Panowa D, Wulfson NS (1974) Steroid saponines and sapogenins. IV. Saponins from Tribulus terrestris. Planta Medica pp. 231237.

23. Wang J1, Zu X, Jiang Y (2009) Five furostanol saponins from fruits of Tribulus terrestris and their cytotoxic activities. Nat Prod Res 23: 14361444

24. Kostova I, Dinchev D (2005) Saponins in Tribulus terrestris: Chemistry and Bioactivity. Phytochem Rev 4: 111-137.

25. Su L, Chen G, Feng SG, Wang W, Li ZF, et al. (2009) Steroidal saponins from Tribulus terrestris. Steroids 74: 399-303.

26. Xu YX, Chen HS, Liang HQ Gu ZB, Liu WY, et al. (2000) Three new saponins from Tribulus terrestris. Planta Med 66: 545-550.

27. Xu YJ, Xu TH, Zhou HO, Li B, Xie SX, et al. (2010) Two new furostanol saponins from Tribulus terrestris. J Asian Nat Prod Res 12: 349-354.

28. Chen G, Su L, Feng SG, Lu X, Wang H, et al. (2013) Furostanolsaponins from the fruits of Tribulus terrestris. Nat Prod Res 27: 1186-1190. 
29. Bhutani SP, Chibber SS, Seshadri TR (1969) Flavonoids of the fruits and leaves of Tribulus terrestris: Constitution of tribuloside. Phytochemistry 8: 299-303.

30. Saleh NA M, Ahmed AA, Abdalla MF (1982) Flavonoid glycosides of Tribulus pentandrus and T. Terrestris. Phytochemistry 21: 1996-2000.

31. Wu TS, Shi LS, Kuo SC (1999) Alkaloids and other constituents from Tribulus terrestris. Phytochemistry 50: 1411-1415.

32. Bedir E, Khan A, Walker LA (2002) Biologically active steroidal glycosides from Tribulus terrestris. Pharmazie 57: 491-493.

33. Zhang S, Li H, Yang SJ (2010) Tribulosin protects rat hearts from ischemia/reperfusion injury. Acta Pharmacol Sin 31: 671-678.

34. Yan W, Ohtani K, Kasai R, Yamasaki K (1996) Steradial saponins from fruits of Tribulus terrestris. Phytochemistry 42: 1417-1422.

35. Hostettmann K, Marston A (1995) Saponins, chemistryand pharmacology of natural products. ( $1^{\text {st }}$ Edn.), Cambridge, United Kingdom. Cambridge, UK: Cambridge University Press, pp. 239-284.

36. Wang ZF, Wang BB, Zhao Y, Wang FX, Sun Y, et al. (2016) Furostanol and spirostanol saponins from tribulus terrestris. Molecules in press 21(4): 429.

37. Parekh J, Jadeja D, Chanda S (2005) Efficacy of aqueous and methanol extracts of some medicinal plants for potential antibacterial activity. Turk J Biol 29: 203-210.

38. Hassan HS, Sule MI, Musa AM, Musa KY, Abubakar MS, et al. (2012) Anti-inflammatory activity of crude saponin extracts from five Nigerian medicinal plants. Afr J Tradit Complement Altern Med 9: 250-255.

39. Francis G, Kerem Z, Makkar HP, Becker K (2002) The biological action of saponins in animal systems: a review. Br J Nutr 88: 587-605.

40. Guclu-Ustundag A, Mazza G (2007) Saponins: Properties, applications and processin. Crit Rev Food SciNutr 47: 231-258.

41. Brain KR, Fry F, Hardman R, Wood AB (1968) The rapid quantitative determination of $\mathrm{C} 27$ epimeric steroidal sapogenins in plants. Phytochemistry 7: 1815-1823.

42. Chu S, Qu W, Pang X, Sun B, Huang X (2003) Effect of saponin from Tribulus terrestris on hyperlipidemia. Zhong Yao Cai 26: 341-344.

43. Li M, Qu W, Wang Y, Wan H, Tian C (2002) Hypoglycemic effect of saponin from Tribulus terrestris. Zhong.Yao Cai 25: 420-422.

44. Sun B, Qu WJ, Zhang XL, Yang HJ, Zhuang XY, et al. (2004) Investigation on inhibitory and apoptosis-inducing effects of saponins from Tribulus terrestris on hepatoma cell line BEL-7402. Zhongguo Zhong Yao Za Zhi 29: 681-684.

45. Jiji J, Visalakshi S, Meenakshi P, Rathi MA, Thirumoorthi LD (2009) Antilipidemic activity of Cissus quadrangularis and Tribulus terrestris on obesity in high fat fed rats. Pharmacology online 2:1250-1258.

46. Protich M, Tsvetkov D, Nalbanski B, Stanislavov R, Katsarova M (1983) Clinical trial of the preparation Tribestan in infertile men. Akush Ginekol 22: $326-329$

47. Neychev VK, Nikolova E, Zhelev N, Mitev (2007) Saponins from Tribulus terrestris $L$ are less toxic for normal human fibroblasts than for many cancer lines: influence on apoptosis and proliferation. Exp Biol Med 232: 126-133.

48. Li M, Guan Y, Liu J, Zhai F, Zhang X, et al. (2013) Cellular and Molecular mechanisms in vascular smooth muscle cells by which total saponin extracted from tribulus terrestris protects against artherosclerosis. Cell Physiol Biochem 32: 1299-1308.

49. Dzau VJ, Braun-Dullaeus RC, Sedding DG (2002) Vascular proliferation and atherosclerosis: New perspectives and therapeutic strategies. Nat Med 8: 1249-1256

50. Touyz RM, Schiffrin EL (2000) Signal transduction mechanisms mediating the physiological and pathophysiological actions of angiotensin II in vascular smooth muscle cells. Pharmacol Rev 52: 639-672.
51. Shi CJ, Qu WJ, Wang JS, Deng TT (2009) Effect of tribu saponin from Tribulus terrestris on the formation of atherosclerosis in rats. Nat Prod Res Dev 21: 53-57.

52. Liu XM, Huang QF, Zhang YL, Lou JL, Liu HS, et al. (2008) Effects of Tribulus terrestris $L$ saponion on apoptosis of cortical neurons induced by hypoxia-reoxygenation in rats. Chin J Integr Med 6: 45-50.

53. Lu WW, Qu JB, Yang SJ (2006) Influences of GSTT on hemodynamics and oxygen metabolism in anesthetic thoraco-opened dogs. J Jilin Univ 32: 379-382.

54. Sun W, Li H, Yang SJ (2008) A triterpenesaponin from Tribulus terrestris attenuates apoptosis in cardiocyte via activating PKC signalling transduction pathway. J Asian Nat Prod Res 10: 39-48.

55. Kim HJ, Kim JC, Min JS, Kim MJ, Kim JA, et al. (2011) Aqueous extract of Tribulus terrestris Linn induces cell growth arrest and apoptosis by down-regulating NF- $\kappa \mathrm{B}$ signaling in liver cancer cells. J Ethnopharmacol 136: $197-203$

56. Hong CH, Hur SK, Oh OJ, Kim SS, Nam KA, et al. (2002) Evaluation of natural products on inhibition of inducible Cyclooxygenase (COX-2) and Nitric Oxide Synthase (iNOS) in cultured mouse macrophage cells. J Ethnopharmacol 83: 153-159.

57. Tuncer MA, Yaymaci B, Sati L, Cayli S, Acar G, et al. (2009) Influence of Tribulus terrestris extract on lipid profile and endothelial structure in developing atherosclerotic lesions in the aorta of rabbits on a highcholesterol diet. Acta Histochem 111: 488-500.

58. Mishra NK, Biswal GS, Chowdary KA, Mishra G (2013) Anti-arthritic activity of Tribulusterrestris studied in Freund's Adjuvant induced arthritic rats. J Pharmaceutical Edu Res 4: 41-46.

59. Angelova S, GospodinovaZ, Krasteva M, Antov G, Lozanov V, et al. (2013) Antitumor activity of Bulgarian herb Tribulus terrestris L. on human breast cancer cells. J Biosci Biotech 2: 25-32.

60. De Gruijl RR (2012) Photocarcinogenesis: UVA vs. UVB radiation. Skin pharmacology applied skin physiology 15: 316-320.

61. Afaq F, Adhami VM, Ahmad N, Mukhtar H (2002) Botanical antioxidants for chemoprevention of photocarcinogenesis. Front Biosci 7: 784-792.

62. Kraemer KH (1997) Sunlight and skin cancer: Another link revealed. Proc Natl Acad Sci USA 94: 11-14.

63. Fisher GJ, Datta SC, Talwar HS, Wang ZQ, Varani J, et al. (1996) Molecular basis of sun-induced premature skin ageing and retinoid antagonism. Nature 379: 335-339.

64. Kulms D, Schwarz T (2000) Molecular mechanisms of UV-induced apoptosis. Photodermatol Photoimmunol Photomed 16: 195-201.

65. Kripke ML, Cox PA, Alas LG, Yarosh DB (1992) Pyrimidine dimers in DNA initiate systemic immunosuppression in UV-irradiated mice. Proc Natl Acad Sci USA 89: 7516-7520.

66. Menzies SW, Greenoak GE, Reeve VE, Gallagher CH (1991) Ultraviolet radiation-induced murine tumors produced in the absence of ultraviolet radiation-induced systemic tumor immunosuppression. Cancer Res 51: 2773-2779.

67. Granstein RD, Sober AJ (1982) Current concepts in ultraviolet carcinogenesis. Proc Soc Exp Biol Med 170: 115-125.

68. Patrick MH (1977) Studies on thymine-derived UV photoproducts in DNA-I. Formation and biological role of pyrimidine adducts in DNA. Photochem Photobiol 25: 357-372.

69. Sinha RP, Häder DP (2002) UV-induced DNA damage and repair: A review. Photochem and Photobiol Sci 4: 225-236.

70. DeLaat WL, Jaspers NG, Hoeijmakers HJ (1999) Molecular mechanism of nucleotide excision repair. Genes Dev 13: 768-785.

71. Kraemer KH (1997) Sunlight and skin cancer: Another link revealed. Proc Natl Acad Sci U S A 94: 11-14.

72. Kulms D, Schwarz T (2002) Independent contribution of three different 
pathways to ultraviolet-B-induced apoptosis. Biochem Pharmacol 64: 837-841.

73. Murphy G, Young AR, Wulf HC, Kulms D, Schwarz T (2001) The molecular determinants of sunburn cell formation. Exp Dermatol 10: 155-160.

74. Ziegler A, Jonason JS, Leffel DW, Simon JA, Sharma HW, et al. (1994) Sunburn and p53 in the onset of skin cancer. Nature 372: 773-776.

75. Kroemer G (1997) The proto-oncogene Bcl-2 and its role in regulating apoptosis. Nat Med 3: 614-620.

76. Reed JC (1997) Double identity for proteins of the Bcl-2 family. Nature 387: 773-776.

77. Washio F, Ueda M, Ito A, Ichihashi M (1999) Higher susceptibility to apoptosis following ultraviolet $\mathrm{B}$ radiation of Xeroderma pigmentosum fibroblasts is accompanied by upregulation of p53 and downregulation of bcl-2. Brit J Dermatol 140: 1031-1037.

78. Luo X, Budihardjo I, Zou H, Slaughter C, Wang X (1998) Bid, a Bcl-2 interacting protein, mediates cytochrome c release from mitochondria in response to activation of cell surface death receptors. Cell 94: 481490.

79. Tyrrell RM (1995) Ultraviolet radiation and free radical damage to skin. Biochem Soc Symp 61: 47-53.

80. Black HS, Lambert CR (2001) Radical reactions of carotenoids and potential influence on UV carcinogenesis. Curr Probl Dermatol 29: 140156.

81. Bongarzone ER, Pasquini JM, Soto EF (1995) Oxidative damage to proteins and lipids of CNS myelin produced by in vitro generated reactive oxygen species. J Neurosci Res 41: 213-221.

82. Farber JL (1994) Mechanism of cell injury by activated oxygen species. Environ Health Perspect 102: 17-24.

83. Cai BX, Jin SL, Luo D, Lin XF, Gao J (2009) Ginsenoside Rb1 suppresses ultraviolet radiation-induced apoptosis by inducing DNA repair. Biol Pharm Bull 32: 837-841.

84. Afnan Q Kaiser PJ, Rafiq RA, Nazir LA, Bhushan S, et al. (2016) Glycyrrhizic acid prevents ultraviolet-B-induced photodamage: a role for mitogen-activated protein kinases, nuclear factor kappa B and mitochondrial apoptotic pathway. Exp Dermatol 25: 440-446.

ISSN: 2574-1241

DOI: 10.26717/BJSTR.2019.16.002911

Margherita Sisto. Biomed J Sci \& Tech Res

(C) Commons Attribution 4.0 License

Submission Link: https://biomedres.us/submit-manuscript.php
85. Molho-Pessach V, Lotem M (2005) Ultraviolet radiation and cutaneous carcinogenesis. Curr Probl Dermatol 35: 14-27.

86. Stege H, Roza L, Vink AA, M, Ruzicka T, Grether-Beck S, et al. (2000) Enzyme plus light therapy to repair DNA damage in ultraviolet-Birradiated human skin. Proc Natl Acad Sci U S A 97: 1790-1795.

87. Shuck SC, Short EA, Turchi JJ (2008) Eukaryotic nucleotide excision repair: from understanding mechanisms to influencing biology. Cell Res 18: $64-72$.

88. Vasquez KM, Christensen J, Li L, Finch RA, Glazer PM (2002) Human XPA and RPA DNA repair proteins participate in specific recognition of triplex-induced helical distortions. Proc Natl Acad Sci U S A 99: 58485853.

89. Lemmon CR, Woo JH, Tully E, Wilsbach K, Gabrielson E (2011) Nuclear factor kappaB (NF-kappaB) mediates a protective response in cancer cells treated with inhibitors of fatty acid synthase. J Biol Chem 286: 31457-31465.

90. Tilstra JS, ClausonCL, Niedernhofer LJ, Robbins PD (2002) NF-kB in aging and disease. Aging Dis 2: 449-465.

91. Crowell JA, Steele VE, Sigman CC, Fay JR (2003) Is inducible nitric oxide synthase a target for chemoprevention?. Mol Cancer Ther 2: 815-823.

92. Seitz CS, Lin Q Deng H, Khavari PA (1998) Alterations in NF-kappaB function in transgenic epithelial tissue demonstrate a growth inhibitory role for NF kappaB. Proc Natl Acad Sci U S A 95: 2307-2312.

93. Manna SK, Mukhopadhyay A, Aggarwal BB (2000) Resveratrol suppresses TNF induced activation of nuclear transcription factors NFkappaB, activator protein-1, and apoptosis: potential role of reactive oxygen intermediates and lipid peroxidation. J Immunol 164: 65096519.

94. Baeuerle PA, Baichwal VR (1997) NF-kappaB as a frequent target for immunosuppressive and anti-inflammatory molecules. Adv Immunol 65: 111-137.

95. Fujioka S, Sclabas GM, Schmidt C, Niu J, Frederick WA, et al. (2002) Inhibition of constitutive NF- $\kappa \mathrm{B}$ activity by $\mathrm{IB} \alpha \mathrm{M}$ suppresses tumorigenesis. Oncogene 22: 1365-1370.

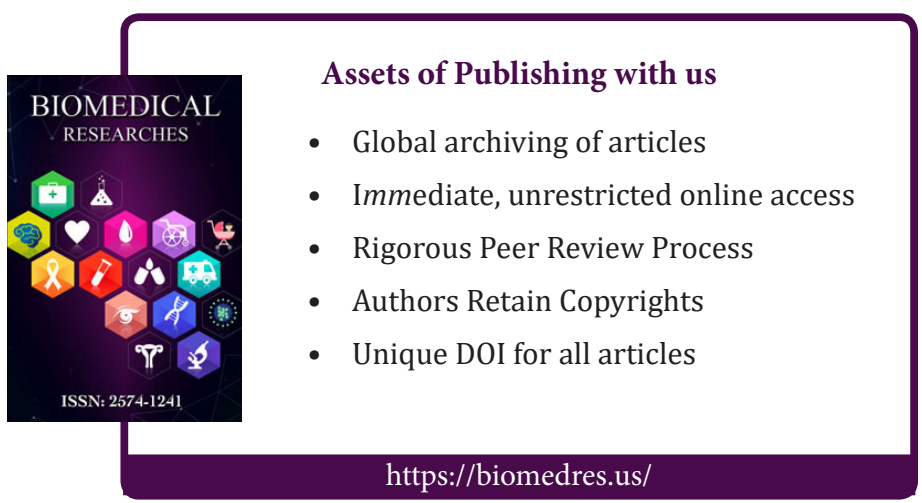

